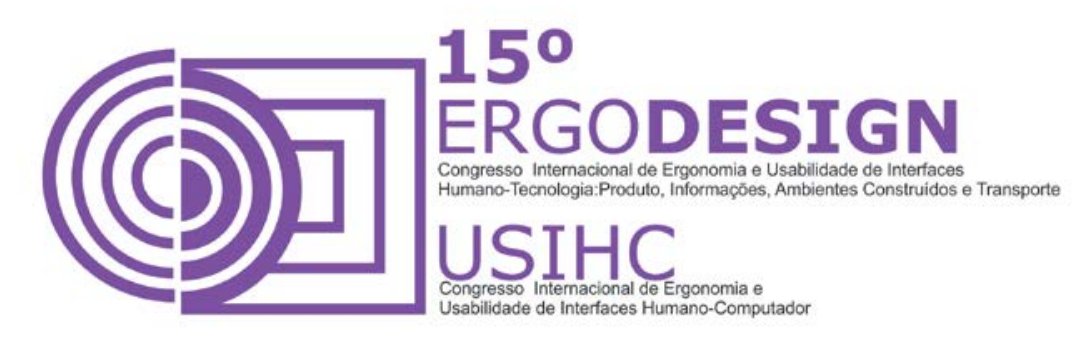

\title{
DESIGN CENTRADO NA CRIANÇA: ESTUDO DE RECOMENDAÇÕES PARA UMA BOA EXPERIÊNCIA
}

\section{CHILD-CENTERED DESIGN: STUDY RECOMMENDATIONS FOR A GOOD EXPERIENCE}

\author{
BISSOLOTTI, Katielen (1); \\ GONÇALVES, Berenice (2); \\ PEREIRA, Alice Theresinha Cybis (3). \\ (1) Universidade Federal de Santa Catarina, Mestranda \\ e-mail:kaathyie@gmail.com \\ (2) Universidade Federal de Santa Catarina, Dra. \\ e-mail: berenice@cce.ufsc.br \\ (3) Universidade Federal de Santa Catarina, Dra. \\ e-mail: acybis@gmail.com
}

\begin{abstract}
RESUMO
A utilização dos dispositivos digitais por crianças e adultos apresenta diferenças. Assim, há necessidade de se estruturar recomendações que estejam em consonância com o design centrado no ser humano $(\mathrm{DCH})$ e adaptá-los ao que se intitula design centrado na criança. Portanto, esta pesquisa propõe identificar recomendações do $\mathrm{DCH}$, de forma que sejam adaptados para projetos voltados ao desenvolvimento de dispositivos digitais voltado à criança. Foram analisadas diferenças entre o perfil cognitivo de crianças e adultos tendo em vista soluções de usabilidade. Por fim, foram apresentadas pesquisadas e soluções de projetos objetivaram melhorar a experiência do usuário criança.

Palavras Chave: design centrado no humano; experiência; recomendações; usabilidade.
\end{abstract}

\section{ABSTRACT}

The use of digital devices by children and adults differs. Thus, there is need to structure recommendations that are consistent with human centered design (HCD) and adapt them to what is entitled to child-centered design. Therefore, this research proposes to identify the $\mathrm{DCH}$ recommendations, so that they are adapted to projects aimed at developing digital devices aimed at children. We analyzed differences between the cognitive profile of children and adults with a view of usability solutions. Finally, we researched and 


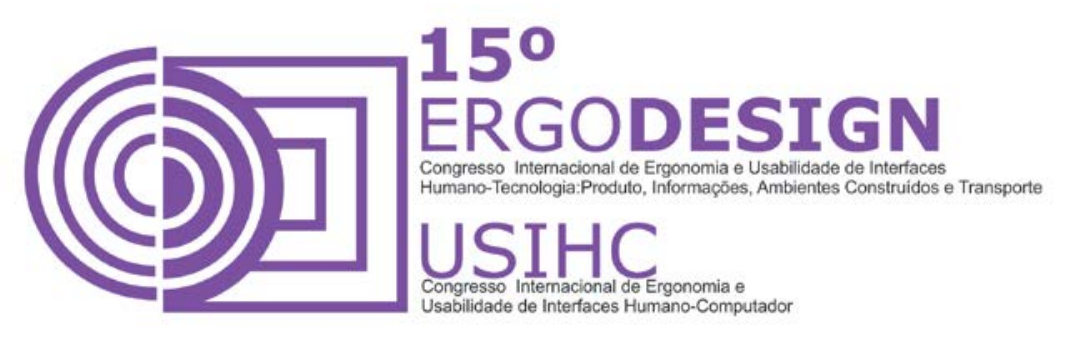

presented solutions projects aimed to improve the user experience of the child.

Keywords: human-centered design; experience; recommendations; usability.

\section{INTRODUÇÃO}

$\mathrm{Na}$ atualidade, crianças que nem alfabetizadas estão, já possuem ou utilizam algum dispositivo digital, como os smartphones e tablets. Com essa disponibilidade de avanços e recursos tecnológicos, cada vez mais se busca por interfaces amigáveis, que poupem esforços e facilitem a navegação.

Donald Norman (2002), afirma que as pessoas costumam se sentir culpadas quando comentem erros na utilização de interfaces e procuram até escondê-los, sentindo-se ignorantes. O que essas pessoas não sabem é que outros, provavelmente, enfrentem as mesmas dificuldades. Ele justifica que isso acontece, na realidade, em virtude de um projeto falho. Para Jakob Nielsen (2000), um sistema deve ser fácil de aprender, de forma que o usuário consiga rapidamente iniciar o trabalho, e ser fácil de ser lembrado em uma segunda utilização. Além disso, deve ser eficiente, cumprindo o que se propõe; ter poucos erros, prevenindo falhas por parte do usuário e fornecendo maneiras de recuperação; e ser agradável, propiciando uma experiência positiva ao usuário.

Neste artigo, o conceito de "design centrado na criança" é particularmente usado para designar os estudos das recomendações utilizadas no design centrado no ser humano, voltado às crianças. Mesmo considerando a validade de tal abordagem, é recomendável adotar suas prescrições como verdades gerais e apriorísticas. Pois, como ocorre o processo de navegação das crianças com os dispositivos digitais? É fácil de usar, é possível que elas controlem esse dispositivo sem ajuda de um adulto? A sua experiência é tão o até mais importante do que do usuário adulto. Para isso, precisa-se identificar o que os pesquisadores estão revelando sobre 0 design centrando na criança, estudando suas recomendações.

Assim, o objetivo do presente estudo é analisar os principais autores que abordam recomendações sobre design centrando no ser humano, focando essas recomendações para que sejam adaptados às crianças. Essa pesquisa realizou-se a partir de um método de revisão bibliográfica, com o objetivo de registrar e compreender diferentes recomendações para uma boa experiência das crianças, sua importância e sua aplicação em dispositivos digitais.

A reflexão crítica proposta neste artigo que, especificamente, trata das experiências das crianças na utilização dos novos dispositivos interativos, também, apresenta recomendações de design centrando no ser humano, mas amplamente direcionado para outro foco de pesquisa, as crianças.

\section{ABORDAGEM DO DESIGN CENTRADO NO SER HUMANO}

Segundo Krippendorff (2000), o design centrado no ser humano (DCH) preocupa-se com a maneira que as pessoas veem, interpretam e convivem com artefatos. Para Giacomin (2012), o 


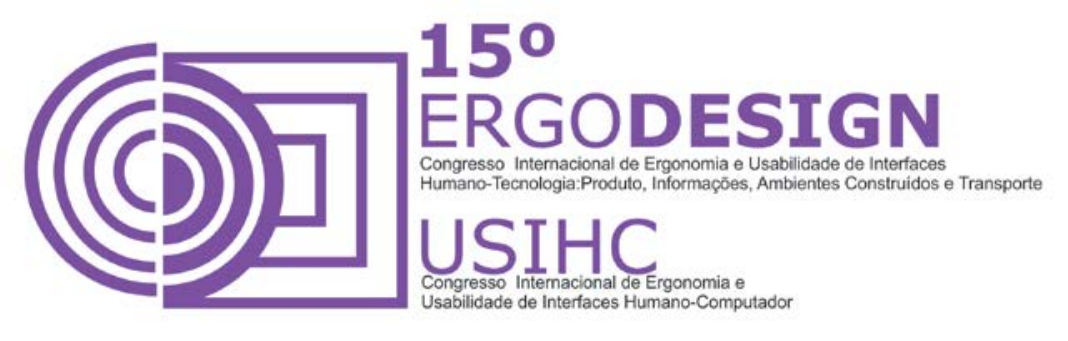

DCH possui suas raízes em áreas semicientíficas como ergonomia, ciência da computação e inteligência artificial, sendo baseado em técnicas que comunicam, interagem, enfatizam e estimulam o envolvimento de pessoas obtendo assim o entendimento de desejos, necessidades e experiências, que normalmente transcendem a própria percepção dessas pessoas.

Como exemplo pode-se considerar a abordagem da IDEO ${ }^{1}$. Na IDEO, o DCH está inserido no contexto de design thinking, que é definido por Tim Brown (2008), como "uma metodologia que imbui a todo o espectro de atividades relacionadas à inovação com valores fundamentais do design centrado no ser humano". Ainda de acordo com Brown (2008), o DCH adota a observação, a captura insights inesperados e produzir a inovação, que refletirão exatamente 0 que os consumidores querem.

O DCH também pode ser definido a partir das normas técnicas internacionais, a Internacional Organization for Standardization, ISO 9241-210 - Ergonomia da interação humano-sistema parte 210: Projeto centrado no ser humano para sistemas interativos. A norma recomenda seis princípios:

- projeto baseado em um entendimento explícito de usuários, tarefas e ambientes;

- os usuários são envolvidos em todo o projeto e desenvolvimento;

- o projeto é conduzido e refinado por uma avaliação centrada no usuário;

- o processo é interativo;

- o projeto aborda a experiência do usuário como um todo;

- a equipe de projeto inclui competências e perspectivas multidisciplinares.

Depois de entender a abordagem do design centrado no ser humano, percebe-se a orientação que ele fornece para compreensão do comportamento do usuário, ajudando a descobrir a resposta mais eficaz às necessidades das pessoas.

\section{EXPERIÊNCIA DE USUÁRIO}

A experiência do usuário preocupa-se em entender como é o comportamento do produto e a sua utilização por pessoas reais. Mais especificamente, Rogers et al. (2013, p.13) afirmam que a experiência de usuário diz respeito a como as pessoas se sentem em relação a um produto e ao prazer e à satisfação que obtêm ao usá-lo, olhá-lo, abri-lo ou fechá-lo.

Um aspecto importante é a qualidade da experiência que alguém tem, seja ela rápida, como recarregar um telefone celular, vagarosa, como jogar com um brinquedo interativo, ou integrada, como visitar um museu (LAW et al., 2009 apud Ibid p.13).

\footnotetext{
${ }^{1}$ É uma empresa global de design premiado que leva uma abordagem baseada em projeto centrado no ser humano para ajudar as organizações nos setores públicos e privado a inovar e crescer.
} 


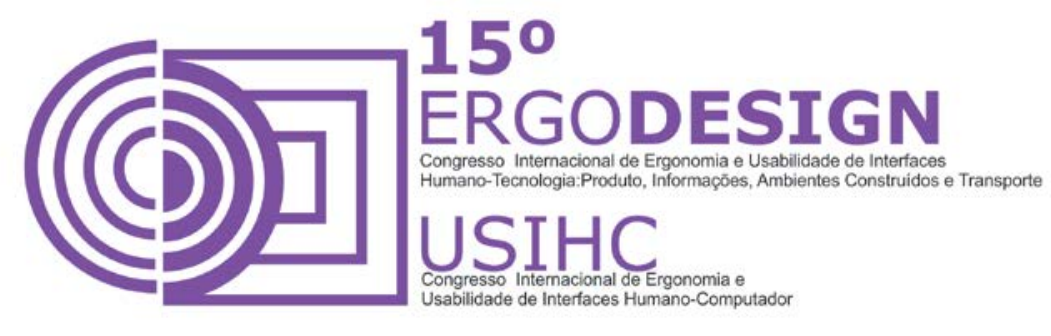

Dessa forma, as metas da experiência de usuário preocupam-se em explicar o comportamento que o usuário tem a partir de sua experiência, por exemplo, se é esteticamente divertido. Essa experiência inclui todas as crenças, preferências, emoções, comportamento e repostas físicas do usuário na utilização, sendo experiências desejáveis quanto indesejáveis, como apresentado no Quadro1, elaborado por Rogers et al., (2013):

Quadro 1 - Aspectos Desejáveis e Indesejáveis da Experiência de Usuário

\begin{tabular}{|lll|}
\hline \multicolumn{3}{|c|}{ Aspectos desejáveis } \\
\hline Satisfatório & Prestativo & Divertido (fun) \\
Agradável & Motivador & Instigante \\
Atraente (engaging) & Desafiador & Surpreendente \\
Prazeroso (pleasure) & Melhora a sociabilidade & Recompensador \\
Emocionante/excitante & Apoia a criatividade & Emocionalmente gratificante \\
Interessante (entertaining) & Cognitivamente estimulante & \\
\hline \multicolumn{3}{|c|}{ Aspectos indesejáveis } \\
\hline Tedioso & Desprazeroso \\
Frustrante & Condescendente (patronizing) \\
Faz com que alguém se sinta & Faz com que alguém se sinta \\
culpado & estúpido & \\
Irritante & Forçosamente bonito (cutesy) \\
Infantil & Artificial/Falso (gimmicky) \\
\hline
\end{tabular}

A compreensão desses parâmetros ajuda a solucionar preocupações como a produtividade durante a utilização dos dispositivos digitais, que desafiam e motivam o usuário para um aprendizado eficaz. Como mostrado no quadro acima, esses aspectos tratam da satisfação do usuário, de como ele se sente durante a interação e, por isso, são subjetivas. O objetivo de desenvolver produtos interativos agradáveis, divertidos e esteticamente agradáveis, segundo Rogers et al., (2013), está na experiência que será proporcionado ao usuário e como ele se sentirá na interação com os dispositivos.

\section{CRIANÇAS VERSUS USUÁRIOS ADULTOS}

Nielsen (2010), em seu estudo sobre usabilidade para web, afirma que chegou a duas conclusões na hora de pensar em usabilidade para crianças. Primeiro ressaltou que crianças e adultos são diferentes e as crianças precisam de um estilo de design que segue diretrizes de usabilidade diferentes. Segundo, muitas das coisas que são feitas para tornar fácil o uso para os adultos, também servem para as crianças, portanto, não é preciso deixar de utilizar as diretrizes que já se conhece, mas sim adaptá-las para esse público-alvo. 


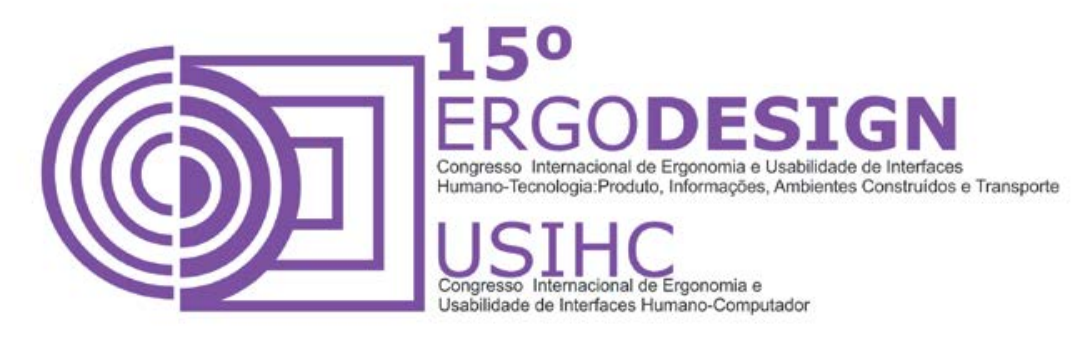

Nielsen (2010) propôs no quadro a seguir (Quadro 2) um resumo das principais semelhanças e diferenças que foram observadas no comportamento do usuário entre crianças e adultos.

Quadro 2 - Semelhanças e diferenças entre crianças e adultos

\begin{tabular}{|c|c|c|}
\hline & CRIANÇA & ADULTO \\
\hline $\begin{array}{c}\text { Objetivo do acesso em } \\
\text { sites }\end{array}$ & Entretenimento & Comunicação \\
\hline As primeiras reações & $\begin{array}{l}\text { Rápido em julgar (e se não é } \\
\text { bom ele sai) }\end{array}$ & $\begin{array}{c}\text { Rápido em julgar (e se não } \\
\text { é bom ele sai) }\end{array}$ \\
\hline Disposição em esperar & Quer gratificação instantânea & Paciência limitada \\
\hline $\begin{array}{l}\text { Seguir convenções de } \\
\text { interface do usuário }\end{array}$ & Preferencial & Preferencial \\
\hline Controle do usuário & Preferencial & Preferencial \\
\hline $\begin{array}{l}\text { Comportamento } \\
\text { exploratório }\end{array}$ & $\begin{array}{l}\text { Gosta de experimentar muitas } \\
\text { opções }\end{array}$ & Fica pelo caminho principal \\
\hline $\begin{array}{l}\text { Múltiplas e redundantes } \\
\text { navegações }\end{array}$ & Muito confuso & Ligeiramente confuso \\
\hline Botão de Voltar & $\begin{array}{l}\text { Não usado (- } 6 \text { anos) } \\
\text { Usado (+ } 6 \text { anos) }\end{array}$ & Usado \\
\hline Leitura & $\begin{array}{l}\text { Nem um pouco (- } 4 \text { anos) } \\
\text { Experimental (- } 6 \text { anos) } \\
\text { Exploração (+ } 6 \text { anos) }\end{array}$ & Exploração \\
\hline Nível de legibilidade & $\begin{array}{c}\text { Nível de ensino de cada } \\
\text { usuário }\end{array}$ & Grau amplo \\
\hline Metáforas da vida real & Muito útil para pré-leitores & Muitas vezes uma distração \\
\hline Tamanho da fonte & $\begin{array}{l}\text { Fonte } 14 \text { (- } 6 \text { anos) } \\
\text { Fonte } 12 \text { (+ } 6 \text { anos) }\end{array}$ & $\begin{array}{c}\text { Fonte } 10 \text { (Até fonte } 14 \text { para } \\
\text { idosos) }\end{array}$ \\
\hline
\end{tabular}




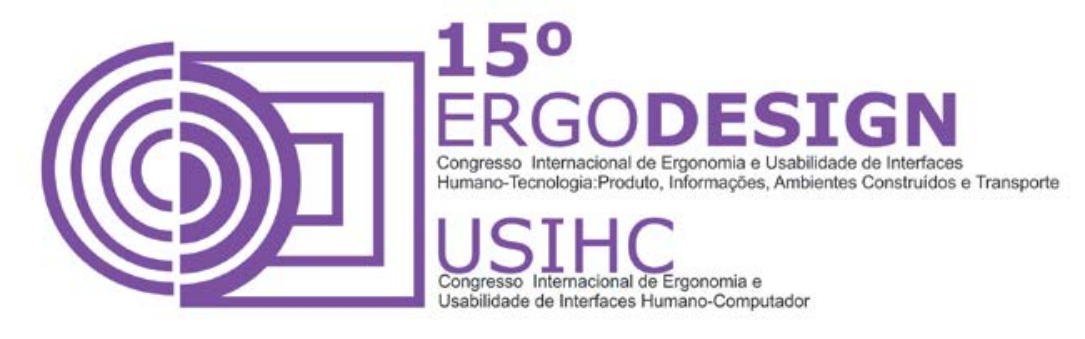

\begin{tabular}{|c|c|c|}
\hline Limitações físicas & $\begin{array}{l}\text { Digitação e manuseio do } \\
\text { mouse lento }\end{array}$ & Nenhum \\
\hline Rolagem & $\begin{array}{c}\text { Evite (- } 6 \text { anos) } \\
\text { Algumas (+ } 6 \text { anos) }\end{array}$ & Alguns \\
\hline Animações e som & Gosta & Normalmente não gosta \\
\hline Propagando e promoções & $\begin{array}{l}\text { Não distingue do conteúdo } \\
\text { real }\end{array}$ & $\begin{array}{l}\text { Anúncios evitados; } \\
\text { promoções vistas com } \\
\text { ceticismo }\end{array}$ \\
\hline $\begin{array}{c}\text { Divulgação de informações } \\
\text { privadas }\end{array}$ & $\begin{array}{l}\text { Normalmente conscientes das } \\
\text { questões: hesitantes em inserir } \\
\text { informações }\end{array}$ & $\begin{array}{l}\text { Muitas vezes, de forma } \\
\text { imprudente disposto a dar } \\
\text { informações pessoais }\end{array}$ \\
\hline Público-alvo & $\begin{array}{l}\text { Crucial, com distinções muito } \\
\text { refinadas entre o público-alvo }\end{array}$ & $\begin{array}{l}\text { Sem importância para a } \\
\text { maioria dos sites }\end{array}$ \\
\hline Pesquisa & $\begin{array}{l}\text { Utilizado por crianças maiores } \\
\text { de } 8 \text { anos }\end{array}$ & $\begin{array}{c}\text { Principal ponto de entrada } \\
\text { para a web }\end{array}$ \\
\hline
\end{tabular}

Após analisar o quadro, é possível verificar que muitas das diretrizes básicas são as mesmas para crianças e adultos, embora muitas vezes com diferenças de grau de usabilidade. Portanto, deve ocorrer um cuidado maior na utilização dessas diretrizes em projetos para crianças é que sejam adaptadas e estendidas, pois, as crianças sofrem de um viés onde elas retornam a utilizar o mesmo método que elas usaram antes para iniciar uma ação. Dessa forma, as diretrizes apresentadas por Nielsen servem, mas são muito gerais, e percebe-se uma necessidade de um projeto mais alinhado com o público infantil.

\section{DESIGN CENTRADO NA CRIANÇA}

As crianças são diferentes dos adultos e por isso é necessário se adotar abordagens diferentes quando se tratado design centrado no ser humano, a fim de criar aplicativos valiosos para esse perfile. Piaget já dizia que:

Crianças não são miniaturas cujo conhecimento simplesmente ainda não chegou ao mesmo nível dos mais velhos; na verdade, elas veem o mundo de um jeito diferente e interagem com ele de maneira totalmente diversa. (COLLIN, 2012, p.265)

Dessa forma, embora o conceito de design centrado no ser humano utilize recomendações importantes, há uma grande limitação no "usuário" (definido aqui como ser humano), que não é considerado especificamente para incluir as crianças.

Por isso, é preciso pensar nessas recomendações, pois as crianças têm um conhecimento diferenciado dos adultos. Contudo, essas diferenças não fazem deles um grupo menos importante e nem justifica que se ignore as crianças na concepção de dispositivos digitais. Ao 


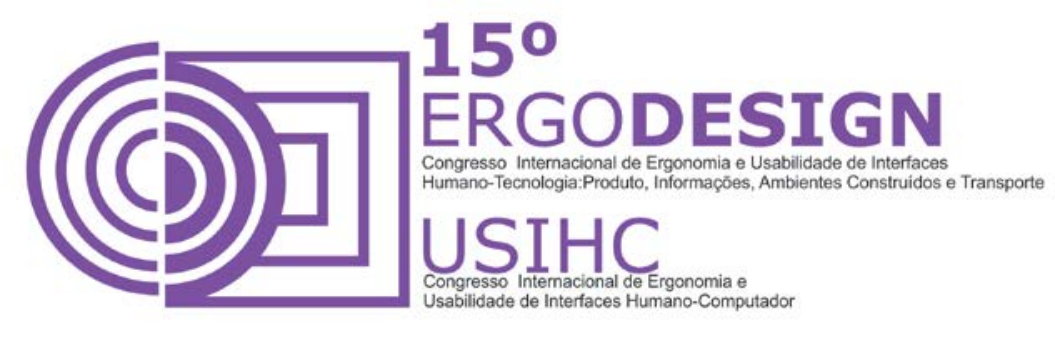

contrário, deve-se levar o que já existe de referências no DCH e aplicá-lo para as crianças. O que temos então é design centrado na criança (DCC) uma área de estudo perfeitamente justificada, esclarece Sabina Idler (2013).

A User Experience Professionals Association (UXPA, 2014) identificou quatro atividades principais que compõem o processo de design centrado no ser humano (especifique o contexto de uso, os requisitos do sistema, produção de soluções de design e a avaliação do projeto). Que a partir dessas atividades, foi remodelado, identificando e aceitando a necessidade do design centrado na criança. Assim, na Figura 1, serão apresentadas essas mudanças.

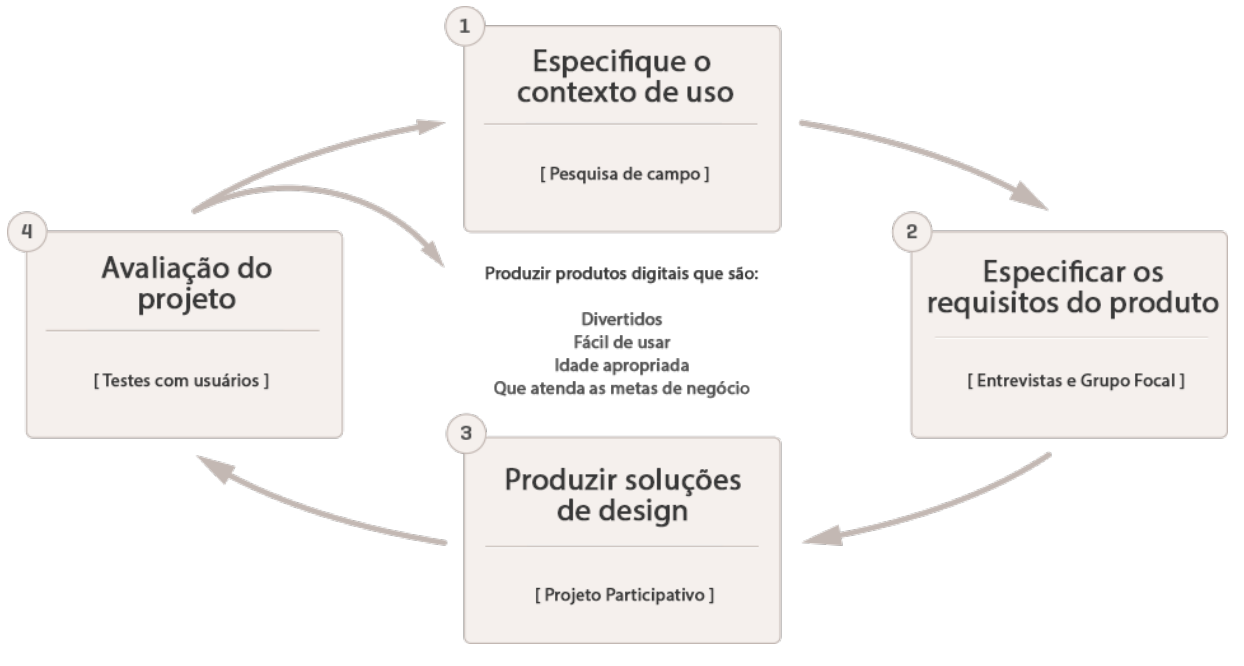

Figura 1 - Modelo de Design Centrado na Criança Fonte: Idler (2012)

1. Especificar o contexto de uso: Segundo a UXPA (2014), deve-se começar com a "identificação das "pessoas" que irão utilizar o produto, para o que eles vão usá-lo, e em que condições eles vão usá-lo". Nesse caso, as pessoas identificadas são crianças. Na compreensão do contexto de uso, é importante a realização de uma pesquisa, onde, uma conversa com os pais, professores e outros, revelarão o modo de interação das crianças. Outra forma de pesquisa, é a observação das mesmas em seu ambiente;

2. Especificar os requisitos do produto: Conhecendo os requisitos do item anterior, deve-se estabelecera faixa etária da criança, pois, dependendo da idade, é preciso observar e/ou envolver a criança para obter insights mais específicos. A UXPA (2014) diz que os "requisitos de negócio e os objetivos de usuários devem ser atendidos para que o produto seja bem sucedido". Por isso, certifique-se de atender a esses interesses, sem perder de vista seus usuários;

3. Criar soluções de design: Com as bases recebidas das análises anteriores, pode-se iniciar a criação das soluções de design. Um projeto participativo é uma ótima maneira de 


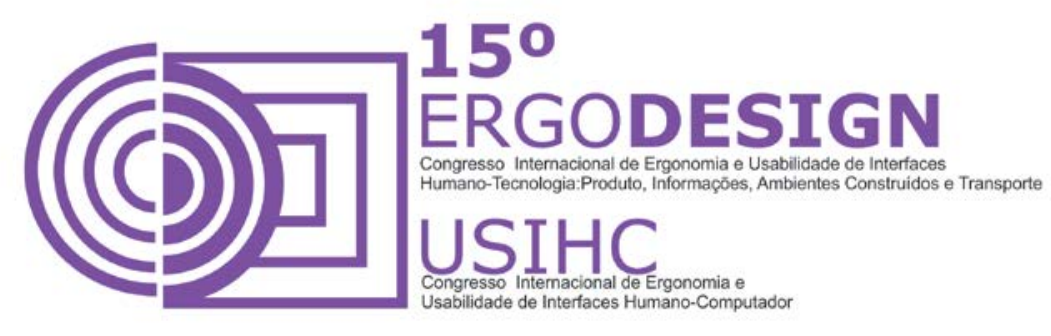

envolver as crianças nessa parte do processo. A criatividade imparcial das crianças pode ser muito libertadora, ajudando os designers a olhar os seus padrões familiares e sua desenvoltura;

4. Avaliar projetos: É o momento de avaliar o projeto, de preferência por meio de testes com seu público-alvo, nesse caso com crianças. Ao desenvolver o produto ele deve ser fácil de usar, mas também tem que ser divertido e envolvente.

\section{RECOMENDAÇÕES PARA UMA BOA EXPERIÊNCIA DE USUÁRIO PARA CRIANÇAS}

Em seu trabalho, Idler (2012) utiliza algumas recomendações de experiência de usuário adaptados e direcionados às crianças. Analisa-se aqui as cinco recomendações:

1. Entretenimento: Os meios digitais para crianças, como sites ou aplicativos, precisam ser divertidos. As crianças usam essas mídias para entretenimento e não para o trabalho ou para ser produtivo. É indispensável ter em mente que as crianças esperam um alto fator de entretenimento - e sua tolerância é bastante baixa. Eles perdem o interesse rapidamente e procuram outra atividade prazerosa;

2. Apelo Visual: $\mathrm{O}$ apelo visual é importante. Um projeto divertido e atraente pode provocar a curiosidade das crianças e motivá-los a começar a usar. Após o uso inicial, o apelo visual ainda é importante - mas não a única recomendação para manter as crianças estimuladas. Ele precisa passar às crianças um sentimento positivo;

3. Usabilidade: As crianças possuem pouca paciência e também um baixo limiar de tolerância. Se a mídia não funciona da maneira que eles esperam, as crianças não gastaram seu tempo em ler as instruções (assumindo que eles podem ler) ou irão gastar mais tempo para descobrir como funciona. A usabilidade deve corresponder as capacidades físicas e cognitivas, bem como as expectativas do grupo etário alvo;

4. Conteúdo apropriado para a idade: O conteúdo desempenha um papel muito importante, coincide com os interesses naturais e modelos mentais para a sua idade-alvo. Com o conteúdo muito simples será facilmente considerado chato, mas, as crianças também têm dificuldades para se concentrar no conteúdo muito complexo. Considerando que as crianças com menos de 12 anos apresentam um rápido desenvolvimento cognitivo, é fundamental para qualquer bom aplicativo, concentrar-se em grupos etários específicos. Se a mídia é desenvolvida para mais de uma faixa etária, é importante oferecer vários níveis de complexidade.

Com isso, para que se entenda melhor o desenvolvimento cognitivo das crianças, Piaget (apud LEFRANÇOIS, 2008, p. 249) descreve cinco estágios que representam os níveis de desenvolvimento da inteligência, na qual cada estágio consiste em um nível mais avançado de adaptação, que são:

- 0-2 anos: a inteligência sensório-motora. Nesse estágio, os bebês aprendem sobre o mundo pelo tato e outros sentidos; 


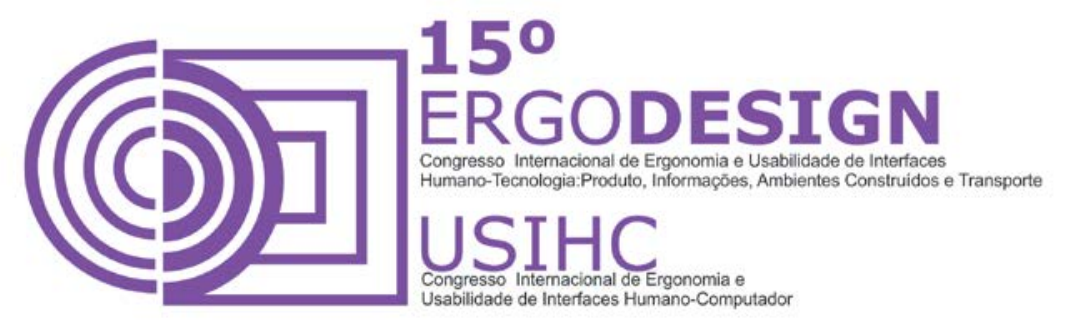

- 2-4 anos: o pensamento preconceitual. Aqui o estágio é caracterizado pela capacidade da criança iniciar a organização dos objetos de forma lógica;

- 4-7 anos: o pensamento intuitivo. O papel da percepção nesse estágio é evidente na falta de conservação da criança, no pensamento egocêntrico e nas dificuldades com os problemas de classificação;

- 7-11 (ou 12) anos: operações concretas. Estabelece-se nesse estágio, um tipo de pensamento pré-lógico, egocêntrico, dominado pela percepção, por um pensamento mais regulado por regras;

- 11-15 anos (dos 11 aos 12 anos ou dos 14 aos 15 anos): operações formais. Nesse último estágio, percebe-se uma completa generalidade do pensamento, sendo um pensamento proporcional, com capacidade de lidar com o hipotético.

5. Incentivar a aprendizagem: Crianças são curiosas por natureza, eles querem aprender, e querem fazer brincando. Conteúdo interessante e novo pode ser divertido e cativante. É importante conhecer as habilidades de seu grupo etário. Para um uso prolongado, é preciso considerar em oferecer vários níveis. Cada novo nível deve adicionar novos desafios para mantê-lo emocionante. Os campos de aprendizagem relevantes para as crianças são as competências linguísticas: vocabulário, pronúncia, leitura, escrita; as habilidades motoras: grandes habilidades motoras e habilidades motoras moderadas; e o pensamento lógico (IDLER, 2012, tradução nossa).

Quadro 3 - Comparação entre os princípios do DCH e as recomendações de boa experiência de Sabine Idler

\begin{tabular}{|c|c|}
\hline Design centrado no ser humano & Idler (2012) \\
\hline \multirow[t]{2}{*}{ O processo é interativo } & $\begin{array}{c}\text { Entretenimento: } \\
\text { Precisa ser divertido, alto índice de } \\
\text { entretenimento, a crianças têm pouca } \\
\text { tolerância e perdem o interesse rapidamente }\end{array}$ \\
\hline & $\begin{array}{l}\text { Apelo Visual: } \\
\text { Deve provocar curiosidade, deve motivá-las, } \\
\text { precisa passar um sentimento positivo }\end{array}$ \\
\hline $\begin{array}{l}\text { O projeto é conduzido e refinado por uma } \\
\text { avaliação centrada no usuário } \\
\text { O projeto aborda a experiência do usuário } \\
\text { como um todo }\end{array}$ & $\begin{array}{l}\text { Usabilidade: } \\
\text { Deve corresponder suas capacidades físicas } \\
\text { e cognitivas, as crianças não vão ler as } \\
\text { instruções, e não possuem paciência }\end{array}$ \\
\hline
\end{tabular}




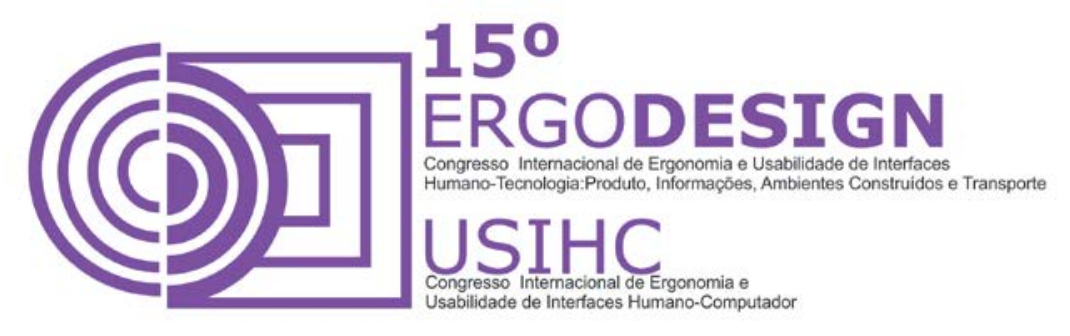

\begin{tabular}{|c|c|}
\hline $\begin{array}{c}\text { Os usuários são envolvidos em todo o } \\
\text { projeto e desenvolvimento }\end{array}$ & $\begin{array}{c}\text { Conteúdo apropriado para a idade: } \\
\text { Deve ser desenvolvido para a faixa etária } \\
\text { correta, possuir vários níveis de } \\
\text { complexidade }\end{array}$ \\
$\begin{array}{c}\text { Projeto baseado em um entendimento } \\
\text { explícito de usuários, tarefas e ambientes }\end{array}$ & $\begin{array}{c}\text { Incentivar a aprendizagem: } \\
\text { A equipe de projeto inclui competências e } \\
\text { perspectivas multidisciplinares }\end{array}$ \\
& $\begin{array}{c}\text { Precisa apresentar um conteúdo } \\
\text { interessante, divertido e cativante, oferecer } \\
\text { vários níveis, novos desafios }\end{array}$ \\
\hline
\end{tabular}

De acordo com o quadro apresentado acima, as principais relações estabelecidas são que o design centrado no ser humano tem foco em todos os usuários, mas não estabelece recomendações básicas com foco no público infantil. Pois, como abordado anteriormente, as crianças são diferentes porque não são adultos. As crianças formam seu próprio grupo-alvo com suas próprias ideias, motivações, habilidades, limitações e preferências. É preciso aprender a envolver as crianças no processo de concepção dos produtos são desenvolvidos. Somente quando é reconhecido as crianças como grupo-alvo autônoma, podemos desenvolver produtos que são divertidas, fáceis de aprender, participar e apoiar as crianças em seu desenvolvimento.

Com essa relação estabelecida, tornou-se possível observar que as recomendações de Idler estão familiarizadas com o conceito de design centrado no ser humano. Exatamente, DCH é a abordagem para o desenvolvimento de produtos com foco claro sobre os usuários. Isso significa que foi identificado e especificado o grupo alvo na hora de desenvolver o produto.

\section{CONSIDERAÇõES FINAIS}

De acordo com o estudo realizado, observa-se que é preciso obter um olhar mais atento sobre as recomendações do design centrado no ser humano. A razão principal é a percepção do estudo para as crianças como grupo alvo. Não há como desenvolver para adultos e criar jogos, sites e aplicativos para crianças tendo as mesmas percepções e recomendações.

Em certas aplicações, é possível adicionar algumas cores e algumas ilustrações e simplificar algumas das interações que os adultos utilizam e que são tão complexos, mas não é o que torna o dispositivo divertido e útil para as crianças. Os adultos têm mais experiência. Isto permite-Ihes, por exemplo, tomar direções em um site e encontrar informações que não parece estar disponível à primeira vista. As crianças muitas vezes não têm essa experiência. Se um site não pode ser usado ou seja, o conteúdo crítico não é fácil de encontrar - a crianças desiste e vai embora. Não importa o quanto qualitativo o conteúdo é, se envolve muito trabalho para encontrar, a maioria das crianças não vão se preocupar.

Enquanto as vantagens de utilizar o DCC podem soar como "bom", os riscos que vêm com quando é ignorado as crianças no processo de design deve ser evitado por todos os meios. As pesquisas com experiências com o usuário não são mais uma opção, é a chave para qualquer bom dispositivo ou aplicativo para crianças. 


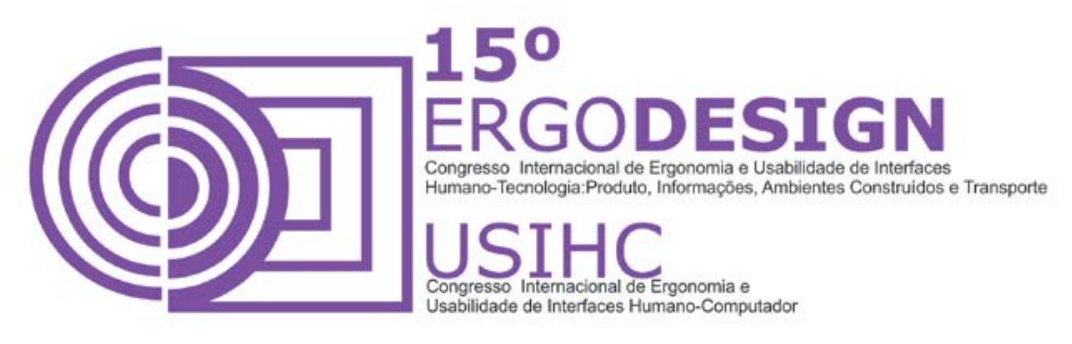

\section{REFERÊNCIAS BIBLIOGRÁFICAS}

BROWN, T. Design Thinking. Harvard Business Review. Junho, 2008. Disponível em: $<$ http://www.ideo.com/images/uploads/thoughts/IDEO HBR Design Thinking.pdf $>$. Acesso em: maio/ 2014.

COLLIN, Catherine; et al. (orgs.). O livro da psicologia. São Paulo: Globo, 2012.

GIACOMIN, J. What is Human Centred Design?.In: X Congresso Brasileiro de Pesquisa em Design, São Luís - MA, Anais. São Luís: EDUFMA, 2012, p.148-161.

IDEO. HCD - HumanCentered Design: Kit de ferramentas. EUA: Ideo, 2009. 102 p. Disponível em: $<$ http://www.ideo.com/work/human-centered-design-toolkit/>. Acesso em: maio/2014.

IDLER, Sabine. UXKids. 2012. <Disponível em: http://uxkids.com/blog>. Acesso em: maio/2014.

ISO 9241-210. Ergonomics of human-centred system interaction - part 210: Human-centred design for interactive systems, International Organization for Standardization, Geneva, Switzerland, 2010.

KRIPPENDORFF, Klaus. Design centrado no usuário: uma necessidade cultural. Estudos em Design, Rio de Janeiro, v. 8, n. 3, p. 87-98, 2000.

LEFRANÇOIS, Guy R. Teorias da Aprendizagem. 5.ed., São Paulo: Cengage Learning, 2008.

NIELSEN, Jakob. Usability Engineering. São Francisco: Academic Academic Press, 1993.

$\overline{2010 .}$ Jakob. Children's Websites: Usability Issues in Designing for Kids. Alertbox, September 13,

NORMAN, D. A. The design of everyday things. New York: Basic Book, 2002.

PASSOS, J.E. Metodologia para o design de interface de ambiente virtual centrado no usuário. Universidade Federal do Rio Grande do Sul, 2010.

ROGERS, Yvonne; PREECE, Jennifer; SHARP, Helen. Design de Interação: Além da interação homemcomputador. 3.ed., Porto Alegre: Bookman, 2013.

UXPA, User Experience Professionals Association. What is User-Centered Design?. Disponível em $<$ http://www.usabilityprofessionals.org/usability_resources/about_usability/ what_is_ucd.html> Acessado em 30 junho 2014. 